\title{
Histopathological Changes in Chronic Low Dose Organic Arsenic Exposure in Rats Kidney
}

\author{
Wan Muhamad Salahudin WS. ${ }^{a}$, Norlelawati A.T. ${ }^{b}$, Nor Zamzila A. ${ }^{b}$, Sanda Aung ${ }^{c}$, Asmah \\ Hanim H. ${ }^{\mathrm{b}}$, Zunariah B. ${ }^{\mathrm{a}}$ \\ ${ }^{a}$ Department of Basic Medical Sciences, Kulliyyah of Medicine, International Islamic University Malaysia. \\ ${ }^{b}$ Department of Pathology and Laboratory Medicine, Kulliyyah of Medicine, International Islamic University Malaysia. \\ 'Department of Basic Medical Sciences, Kulliyyah of Pharmacy, International Islamic University Malaysia.
}

\section{ABSTRACT}

INTRODUCTION: Exposure to environmental arsenic remains a major public health challenge. Human is exposed to arsenic from groundwater as a result of anthropogenic activities. Chronic exposure to inorganic arsenic has been linked with multiple medical conditions. Therefore, many agricultural countries have shifted the use of inorganic to the organic-based herbicide, monosodium methylarsonate (MSMA). However, with increasing numbers of chronic kidney disease of unknown etiology $(\mathrm{CKDu})$, chronic exposure to herbicide is believed as one of the potential explanations. To date, studies on chronic effects of organic arsenic on the kidney are limited. Therefore, this study aimed to investigate the effect of chronic oral organic arsenic exposure on the rat's kidney. MATERIALS AND

METHOD: Thirty-six Sprague Dawley rats were randomly divided into treatment and its corresponding control groups according to the duration of observations either 2, 4 or 6 months. Both groups were subdivided into three subgroups, each with six animals per subgroup. The treatment groups were given oral MSMA at $63.20 \mathrm{mg} / \mathrm{kg}$ body weight, while control groups received distilled water. At the end of each duration, blood was collected for the renal profile, urine for neutrophil gelatinase-associated lipocalin (NGAL) marker, and kidney tissues were harvested for arsenic level measurement and histological analysis. RESULTS: Arsenic level and urinary NGAL were higher in all treatment groups than its corresponding control groups. Histological findings showed progressive pathological changes in the glomeruli and proximal tubules. CONCLUSIONS: Chronic oral exposure to low dose organic arsenic has demonstrated evidence of kidney injury in rats.

KEYWORDS: Low dose organic arsenic, chronic exposure, monosodium methyl arsenate, glomerular and proximal tubule injury

\section{INTRODUCTION}

Exposure to environmental arsenic remains a major public health challenge. World Health Organization (WHO) in 2018 had reported that 140 million people

\section{Corresponding Author:}

Asst. Prof. Dr. Zunariah Buyong

Department of Basic Medical Sciences, Kulliyyah of Medicine,

International Islamic University Malaysia,

Jalan Sultan Ahmad Shah, Bandar Indera Mahkota,

25200 Kuantan, Pahang, Malaysia.

Tel. No: +6095704500

Email: drzuna@iium.edu.my from 50 countries are exposed to arsenic above the recommended level of $10 \mu \mathrm{g} / \mathrm{L} .{ }^{1}$ The major source of arsenic exposure was from groundwater contamination either from tube wells or shallow wells. Arsenic toxicity was suggested to be acquired through oral ingestion. ${ }^{2}$ The main sources of arsenic contamination were coming from anthropogenic activities such as agricultural, industrial, and domestic activities. These activities include the usage of arsenic-based fertilisers, pesticides and herbicides, mining and refining, and efflux of industrial wastes into the water system. ${ }^{3}$ 
Chronic exposure to inorganic arsenic has been known to cause many medical conditions such as diabetes, hypertension, peripheral artery disease, and various tumour formation in the skin, lungs, urinary bladder, liver, and kidneys. ${ }^{4}$ Because of health complications that were caused by inorganic arsenic, the organic arsenical herbicides were introduced in the 1950s. Monosodium methyl arsenate (MSMA) becoming the most popular organic arsenical herbicide due to its low cost, effectiveness, and lower toxicity compared to lead arsenate, inorganic arsenic. Currently, MSMA is widely used for weed control in cotton and on turf and lawn. ${ }^{5}$ Although the shifting to MSMA from inorganic arsenic was due to its less toxic chemical properties, some studies showed that organic arsenic could be as harmful as inorganic arsenic. For example, the methylated arsenic such as methylarsonous acid, MMA(III), is more toxic than inorganic arsenic species (iAsV). ${ }^{6}$ Oral exposure of MSMA may produce more toxic metabolites such as dimethyl arsenic (DMA) species in vivo, including monomethylarsonous acid (MMAIII) and dimethyl arsinic acid (DMA) radicals. ${ }^{7}$ DMA was found to enhance prostate carcinogenesis. ${ }^{8}$

In agricultural countries i.e. Bangladesh and India, Chronic Kidney Disease of Unknown Etiology (CKDu) cases are on the rise. Many factors have been postulated as potential causes such as physical exertion, heat stress, water quality, and exposure to agrochemicals, ${ }^{9}$ but no definite cause has been confirmed. Exposure to agrochemicals such as MSMA has been identified to be one of the risk factors. ${ }^{10}$ Human studies on the chronic toxicity of arsenic and its effects on the kidneys are limited in providing some evidence to support the association between arsenic and kidney disease. ${ }^{11}$ Most studies were focused on the effect of inorganic arsenic over short term duration. ${ }^{12}$ Therefore, this study aimed to explore the effects of chronic low dose exposure of organic arsenic on the rats' kidneys.

\section{MATERIALS AND METHODS}

\section{Ethical Approval}

The research protocol was approved by the Institutional Animal Care and Use Committee (IIUM/504/14/2/ IACUC - Approval/2017 (14)).

\section{Experimental Animal}

A total of 36 Male-Sprague-Dawley rats of approximately 250g, aged 3-4 months old, were purchased from Universiti Putra Malaysia, Selangor. They were housed in polypropylene cages of two animals per cage. Throughout the study, they were maintained in standard experimental conditions of 12:12 hours dark-light cycle, temperature between $25-27^{\circ} \mathrm{C}$ with adequate ventilation. The rats were acclimatised for 7 days and accessed to standard rat chow (Gold Coin Feedmills Sdn. Bhd., Malaysia) and reverse osmosis water ad libitum.

\section{Experimental Design}

Thirty-six rats $(n=36)$ were equally divided into six groups, six animals each $(n=6)$. Three treatment groups (TG 1, TG 2, and TG 3) and their corresponding control groups (CG 1, CG 2, and CG 3). The observation durations were 2,4 and 6 months. The durations, route of administration, and dosage of arsenic exposure were chosen based on the findings of the previous study. ${ }^{13}$ The 6-month exposure in rats is considered as 18-years of human exposure. ${ }^{14}$, 15

\section{MSMA Preparation}

MSMA is an organic arsenic-based herbicide and pesticide. It was purchased from Ancom Corp Sdn. Bhd., Malaysia. The preparation was based on the previous study. ${ }^{13}$ The dosage given to rats was 63.20 mg MSMA per kilogram body weight via oral gavage. The actual arsenic content was approximately $7.30 \mathrm{mg}$, in mimicking arsenic exposure in humans as reported by Mandal \& Suzuki, 2002.16 The dose was also below the WHO permissible limit of $10 \mu \mathrm{g} / \mathrm{mL} .{ }^{17}$

\section{Arsenic Level Measurement}

A total of 36 samples section of kidney tissues taken, six samples from each group and measured for arsenic concentration. The samples were homogenised and digested with a mixture of nitric acid, hydrochloric acid, and hydrogen peroxide. Analysis of sample extracts was performed using Inductive Coupled Plasma Mass Spectrometry (ICPMS) (ELAN9000, Perkinelmer, Canada). 


\section{Renal Function Test}

The blood samples were collected from the orbital sinus under inhalation of diethyl ether anaesthesia. The blood samples were then centrifuged at $4000 \mathrm{rpm}$ (Centrifuge, Nüve, Turkey) for 10-minutes and collected sera were stored at $-70^{\circ} \mathrm{C}$. Before the measurement, the frozen sera were thawed and about $0.5 \mathrm{~mL}$ was used per sample cup. Each sample was measured in duplicate. The sample cups containing the serum were labelled and placed on the sample tray mounted on the Chemistry Analyzer (Cobas Integra 400, Roche Diagnostic, Switzerland). The test was then run at room temperature.

\section{NGAL biomarker}

NGAL concentration in urine was measured using Lipocalin-2 (NGAL) Rat ELISA Kit (ab119602, Abcam) according to the manufacturer's instruction. Four samples from each group $(n=4)$ subjected to the analysis. The concentration of NGAL was proportional to the intensity of the coloured reaction product (450 $\mathrm{nm}$ ). All samples were analysed in triplicate. NGAL level was expressed as ng of protein per $\mathrm{mL}$ of perfusate.

\section{Light Microscopy}

The kidney tissue samples were processed for histological analysis. Samples were fixed in 10\% neutral buffered formalin for at least 24 hours. Then underwent dehydration with graded concentrations of ethanol using an automated tissue processor (Leica TP 1020, Leica Biosystems Inc., Germany). The tissues were then embedded in liquid paraffin wax. Next, the tissues were trimmed and sectioned to $5 \mu \mathrm{m}$ for Haematoxylin \& Eosin (H\&E) and periodic acid-Schiff (PAS) staining. The slides were captured with Digital Scanning System Model of Pannoramic Desk (3D Histech Ltd., Budapest, Hungary).

\section{Statistical analysis}

Data were analysed by using IBM SPSS Statistics for Windows, Version 21.0. (IBM Corp., Armonk, NY). Renal function test and NGAL marker were analysed by student t-test using Graphpad Prism version 8.0.0 for Windows (California, USA). The histological changes were assessed descriptively.

\section{RESULTS}

\section{Arsenic level in the kidney tissue of control and treatment groups}

The levels for control and MSMA treated groups are shown in Figure 1. The arsenic levels in treated groups were significantly higher compared to the corresponding control samples from each group duration. In 2-month groups, the arsenic level in TG1 and CG1 were $98.67 \pm$

Table I. Comparison of the renal function test between the control and the MSMA treated groups.

\begin{tabular}{|c|c|c|c|c|c|c|}
\hline Duration & $\begin{array}{c}\text { Renal } \\
\text { Function } \\
\text { Test }\end{array}$ & $\begin{array}{c}\text { Control }(n=6) \\
\text { Mean } \pm \text { SD }\end{array}$ & $\begin{array}{l}\text { Treatment }(n=6) \\
\text { Mean } \pm \text { SD }\end{array}$ & $\mathbf{t}$ & df & p-value \\
\hline \multirow[t]{5}{*}{2 months } & Sodium & $118.8333 \pm 58.2457$ & $141.8333 \pm 1.7224$ & -0.967 & 5.009 & 0.378 \\
\hline & Potassium & $4.1000 \pm 2.0159$ & $4.9167 \pm 2.0159$ & -0.967 & 10 & 0.356 \\
\hline & Chloride & $83.0000 \pm 40.6743$ & $97.8333 \pm 1.4720$ & 0.893 & 5.013 & 0.413 \\
\hline & Urea & $6.1833 \pm 3.0616$ & $7.8833 \pm 1.0265$ & -1.290 & 10 & 0.226 \\
\hline & Creatinine & $33.5000 \pm 17.7285$ & $43.5000 \pm 9.3113$ & -1.233 & 10 & 0.249 \\
\hline \multirow[t]{5}{*}{4 months } & Sodium & $141.8333 \pm 2.2286$ & $142.0000 \pm 2.8983$ & -0.112 & 10 & 0.913 \\
\hline & Potassium & $5.6500 \pm 2.3072$ & $4.7167 \pm 0.4070$ & 0.976 & 10 & 0.352 \\
\hline & Chloride & $98.1667 \pm 3.7104$ & $99.000 \pm 1.2649$ & -0.521 & 10 & 0.614 \\
\hline & Urea & $8.4333 \pm 1.0367$ & $6.5667 \pm 1.0152$ & 3.151 & 10 & $0.010^{*}$ \\
\hline & Creatinine & $39.5000 \pm 5.4314$ & $39.5000 \pm 5.9582$ & 0.000 & 10 & 1.000 \\
\hline \multirow[t]{5}{*}{6 months } & Sodium & $141.5000 \pm 1.7607$ & $141.1667 \pm 2.1370$ & 0.295 & 10 & 0.774 \\
\hline & Potassium & $4.9500 \pm 0.2510$ & $4.8333 \pm 0.6121$ & 0.432 & 6.635 & 0.679 \\
\hline & Chloride & $98.5000 \pm 1.6432$ & $98.0000 \pm 1.6733$ & 0.522 & 10 & 0.613 \\
\hline & Urea & $7.7667 \pm 0.5989$ & $7.5000 \pm 0.9230$ & 0.594 & 10 & 0.566 \\
\hline & Creatinine & $41.6667 \pm 7.8655$ & $42.6667 \pm 13.1098$ & -0.160 & 10 & 0.876 \\
\hline
\end{tabular}

Independentsample t-test. ${ }^{*} \mathrm{p}$-value $\leq 0.05$ is considered as statistically significant at a $95 \%$ confidence interval 


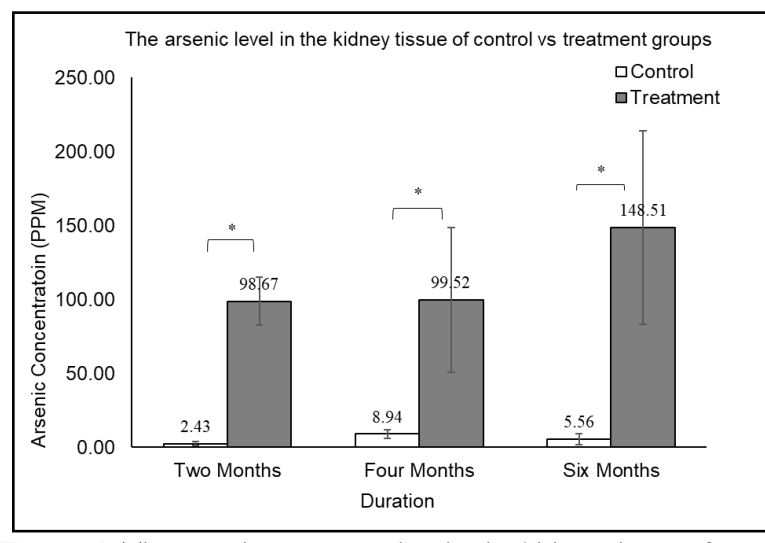

Figure 1. The arsenic concentration in the kidney tissue of control and treatment groups at 2-month, 4-month, and 6-month durations $(* \mathrm{p}<0.05)$

16.12 PPM and $2.43 \pm 1.36 \mathrm{PPM}$, respectively. In 4-month groups, TG 2 and CG2 were $99.52 \pm 49.13$ PPM and $8.94 \pm 2.84$ PPM. While in 6-month groups, the concentration of arsenic in TG3 and CG3 were $148.51 \pm 65.65 \mathrm{PPM}$ and $5.56 \pm 3.71 \mathrm{PPM}$.

\section{Renal function test}

The mean renal function tests in control and MSMA treated groups for all durations are shown in Table I. There was no statistically significant difference in renal function test between control and MSMA treated groups for all durations.

\section{Urine Concentration of NGAL in Control and MSMA Treated Groups}

Generally, MSMA treated groups (TG 1, TG 2 and TG 3) showed higher levels of NGAL concentration compared to control groups (Figure 2). However, only TG $2(3141.92 \pm 346.53 \mathrm{pg} / \mathrm{mL})$, showed a significantly higher level in comparison to its control, CG 2 (2499.67 $\pm 198.64 \mathrm{pg} / \mathrm{mL})(\mathrm{P}=0.018)$.

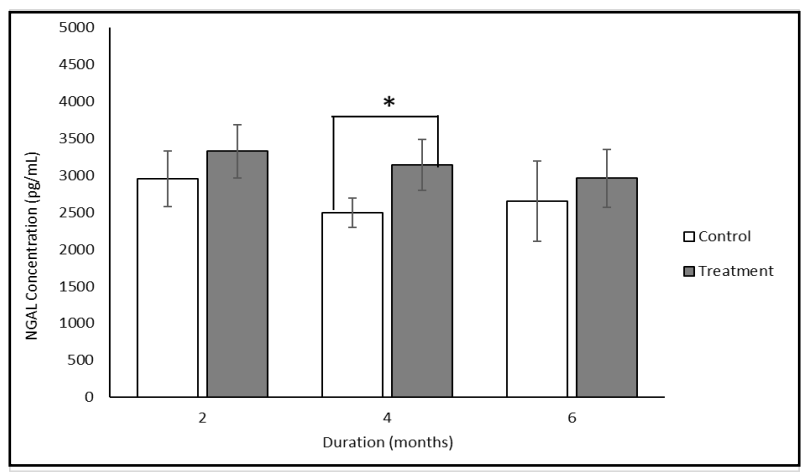

Figure 2 Comparison of the urinary level of NGAL in control and MSMA treated groups in 2-month, 4-month, and 6-month durations. Results presented as mean (SD). Independent sample t-test. ${ }^{*}$ p-value $\leq 0.05$ is considered as statistically significant at a $95 \%$ confidence interval.

IMJM Volume 20 No.1, Jan 2021

\section{Histopathological findings in renal corpuscles}

Glomerular structure in treated groups showed progressive pathological changes according to the duration of exposure to MSMA. In the control group, the glomeruli showed a normal glomerular appearance with a regular Bowman's space (Figure 3A). In 2-month treated group (TG1), minimal changes were observed, such as hypercellularity of glomeruli and reduced Bowman's space (Figure 3B). Meanwhile, in the 4month treated group (TG2), the glomeruli demonstrated atrophy with increased Bowman's space (Figure 3C). Finally, in the 6-month treated group (TG 3), the changes were more severe as glomeruli showed more severe atrophy, areas of sclerosis and marked increased in Bowman's space (Figure 3D).

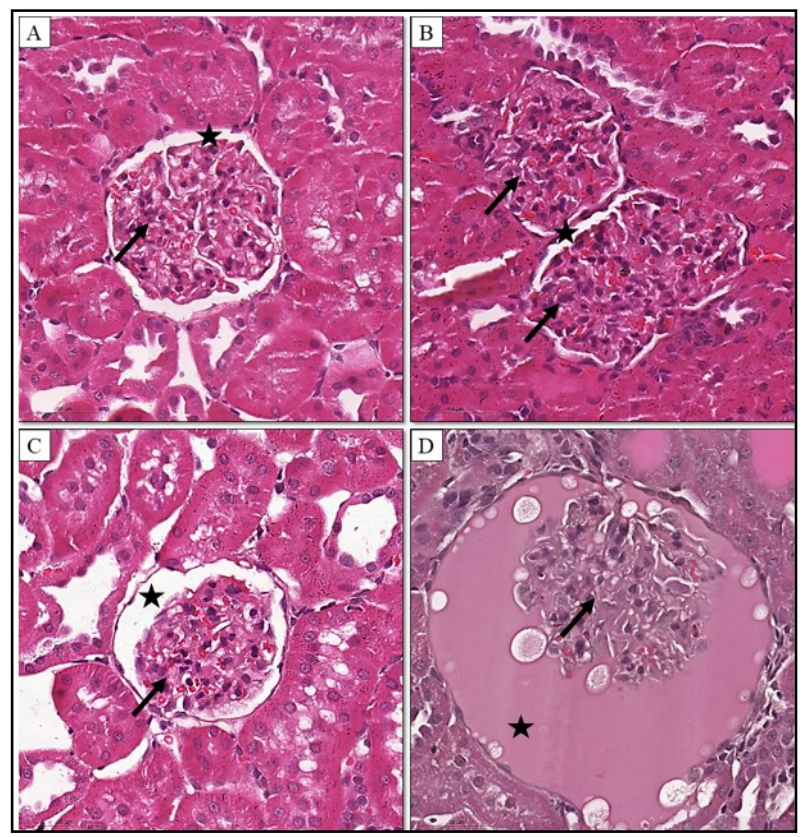

Figure 3 Photomicrograph of kidney section showing renal corpuscles of each group. (A) Control group showing normal morphology of glomerulus (arrow) and Bowman's space (star). (B) TG 1 showing glomerular hypercellularity (arrow) and reduced Bowman's space (star). (C) TG 2 showing glomerular atrophy (arrow) with increased Bowman's space (star). (D) TG 3 showing marked glomerular atrophy and sclerosis (arrow) with a marked increased in Bowman's space (star). (H\&E stain, X400)

\section{Histopathological findings in proximal convoluted tubules}

In control groups, the tubules appeared normal with clear brush border (Figure 4 A). Proximal convoluted tubules (PCT) showed progressive changes in treated groups. In TG 1, no apparent changes were demonstrated and tubules were also normal (Figure 4 B). In TG 2, the lumina of tubules were dilated, some detachment of nuclei which were displaced into the 
lumina and discontinuity of brush border were observed (Figure 4 C). In TG 3, the lumina showed more obvious dilatation, with minimal nuclei located close to the basal membrane and the lumina were filled with a hyaline cast (Figure 4 D).

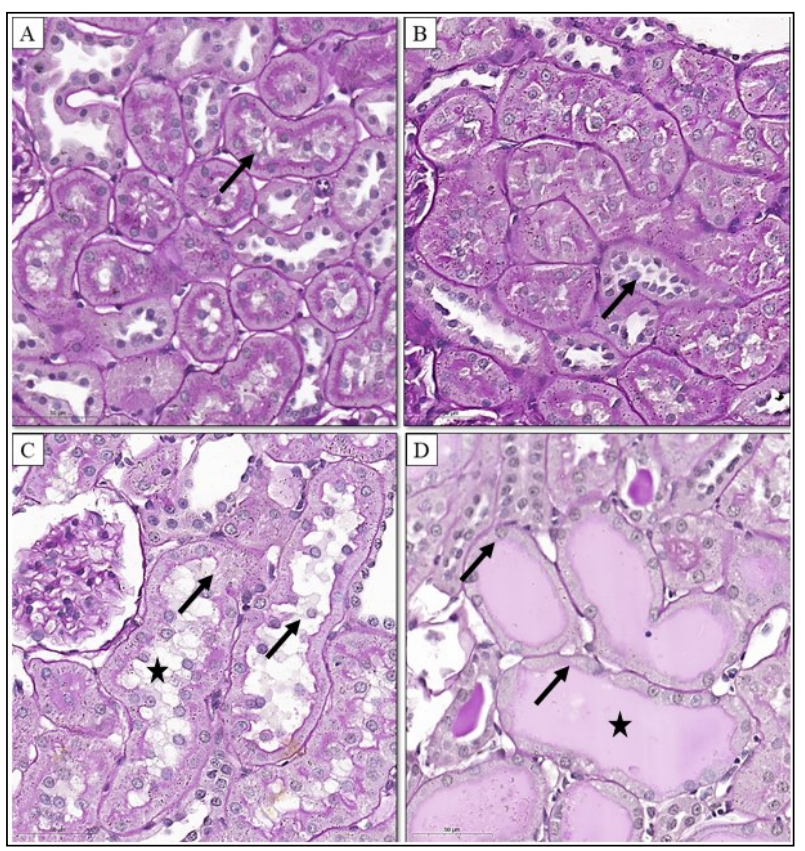

Figure 4 Photomicrograph of kidney section showing the tubules. (A) Control group, showing normal morphology of proximal tubules, in-situ nuclei with clear brush border (arrow). (B) TG 1 is also showing normal proximal tubules (arrow). (C) TG 2 showing dilated lumen of PCT (star), detachment of nuclei, and discontinuity of brush border (arrow). (D) TG 3 shows PCT with marked dilatation of the lumen filled with hyaline cast fluid (star), diminished brush border, and flattening of tubular epithelial cells (arrow). (PAS stain, X400)

\section{DISCUSSION}

Measurement of arsenic level in the tissue is important to confirm the arsenic accumulation in the kidney tissues. The study showed that the arsenic levels in the kidney tissues were found to be higher in all treatment groups as compared to the corresponding control groups of the same durations. The result revealed that the arsenic level was markedly higher in the 4-month treatment group as compared to the 2-month and 6-month treatment groups. In the chronic exposure of arsenic, arsenic was reported to reaccumulate in the proximal tubules. ${ }^{18}$ The total arsenic accumulation in the proximal tubules depends on the dosage and duration of exposure.19,20 The current study showed that the arsenic level was higher in TG 2 than TG1. Therefore, the longer the period of exposure, the more arsenic accumulated in the kidney tissues and more damage to the kidney. The levels of arsenic were in agreement with the progressive histological changes, which showed the most pathological changes in the 6-month treatment group.

Renal function test is one of the commonly used investigations in evaluating the kidney function. Serum urea and creatinine are most widely accepted parameters in the assessment of chronic kidney disease. These metabolic waste products are normally excreted by the kidneys. ${ }^{21}$ In the case of kidney disease, there will be an increase in urea, creatinine and potassium which indicate damaged renal function. The present study showed that chronic exposure of low dose organic arsenic in the rats exhibited no significant differences in the renal profile as compared to the control groups despite progressive changes observed in the glomeruli and tubules of treated animals. A previous study done by Mohssen showed that histological changes appeared earlier than derangement in renal function ${ }^{22}$. It is reported that an elevated serum creatinine can be detected if there is a loss of about $50 \%$ of kidney function. Therefore, a rise in the serum creatinine level is a late marker of acute kidney injury. Its level could be more pronounced later in chronic kidney disease when there is a substantial reduction in the glomerular filtration rate or obstruction to urine elimination. ${ }^{23,24}$ Thus, we recommend future studies to prolong the exposure duration, which expected more extensive damage to the kidney and might result in derangement of renal function.

The urine NGAL is used as kidney injury biomarker to detect early kidney injury. In the kidney, NGAL is mainly secreted from the loop of Henle and collecting ducts. It is expressed by tubular epithelial cells in response to injury and tubulointerstitial damage. ${ }^{25}$ The level of NGAL is also associated with the degree of kidney dysfunction and very useful to monitor the outcome of kidney injury. ${ }^{26}$ The urinary levels of NGAL in treatment groups were relatively at higher concentration, in all durations. The significantly higher level at four months duration is corresponding with the early histological appearance of tubular damage. In two months and six months treatment groups, the levels were not significantly higher compared to control. This could be due to a wider biological variation in urinary NGAL compared to plasma NGAL which reported as its limitations. ${ }^{27-29}$ Nevertheless, the finding in this study suggests that a higher level of urinary NGAL biomarker could be more sensitive than serum renal function test as 
an indicator for early kidney injury.

Histological analysis remains the gold standard in diagnosing kidney injury. ${ }^{24}$ The pathological changes in nephrotoxicity injury are mainly focal and segmental lesions. 30 Previous studies on metal nephrotoxicity, which include arsenic, were primarily focussed on the proximal tubules as the major site of injury. This is because reaccumulation and reabsorption of nephrotoxicants occur at the proximal tubules. 31 However, few studies also showed that glomerulus might also vulnerable in arsenic exposure besides proximal tubules. Involvement of the glomerulus is mainly at the glomerular basement membrane and podocyte. ${ }^{32,33}$ In this study, the initial injury at 2-month group was minimal, which limited to the glomeruli. The glomeruli only showed initial changes such as hypercellularity due to mesangial expansion. Meanwhile, as the duration of exposure progresses, in 4 and 6month treatment groups, the histological changes started to show progressive kidney injury changes such as glomerular atrophy, sclerosis and tubular damage. As the injury worsened, there were necrosis and detachment of epithelial cells of PCT. The cells disintegrated and leaving the cell debris in the lumen. Later, obstructing the tubular lumen, which gives rise to accumulation of hyaline cast and dilatation of tubular lumen. These findings suggest that, in chronic low dose arsenic exposure, the glomeruli and tubules are equally affected.

\section{CONCLUSION}

This study demonstrated the evidence of the detrimental effects of chronic low dose organic arsenic exposure on the kidney. The injury appeared to affect both glomerular and tubular structures. However, the exact mechanism of injury requires future studies to mapping out the pathway of kidney injury. Hence, further intervention is possible to prevent the occurrence of chronic kidney disease.

\section{AUTHOR CONTRIBUTIONS}

All authors contributed toward data analysis, drafting and critically revising the paper and agree to be accountable for all aspects of the work.

\section{DISCLOSURE OF CONFLICT OF INTEREST}

There are no conflicts of interest.

\section{ACKNOWLEDGEMENT}

We would like to express our sincere appreciation to all technical staff of the Department of Basic Medical Sciences and Department of Pathology \& Laboratory Medicine, Kulliyyah of Medicine, IIUM for their assistance. We also would like to acknowledge the Ministry of Higher Education, Malaysia, through the Fundamental Research Grant Scheme (FRGS15-2160457) that has been the source of funding for this research.

\section{REFERENCES}

1. World Health Organization. Arsenic [Internet]. Available from: https://www.who.int/news-room/ fact-sheets/detail/arsenic. 2018 [Accessed 1 April 2020].

2. Wai KM, Umezaki M, Mar O, et al. Arsenic exposure through drinking water and oxidative stress status: A cross-sectional study in the Ayeyarwady region, Myanmar. Journal of Trace Elements in Medicine and Biology 2019; 54: 103-109. DOI: https://doi.org/10.1016/j.jtemb.2019.04.009

3. Smedley PL and Kinniburgh DG. A review of the source, behaviour and distribution of arsenic in natural waters. Applied geochemistry 2002; 17: $517-$ 568. DOI: https://doi.org/10.1016/S0883-2927 (02)00018-5

4. Robles-Osorio ML, Sabath-Silva E and Sabath E. Arsenic-mediated nephrotoxicity. Ren Fail 2015; 37: 542-547. 2015/02/24. DOI: 10.3109/0886022X.2015.1013419.

5. Matteson AR, Gannon TW, Jeffries MD, et al. Arsenic Retention in Foliage and Soil after Monosodium Methyl Arsenate (MSMA) Application to Turfgrass. J Environ Qual 2014; 43: 379-388. 2015/01/21. DOI: 10.2134/ jeq2013.07.0268.

6. Styblo M, Del Razo LM, Vega L, et al. Comparative toxicity of trivalent and pentavalent inorganic and methylated arsenicals in rat and human cells. Arch Toxicol 2000; 74: 289-299. 2000/09/27. DOI: 10.1007/s002040000134. 
7. Albert C, Williams TD, Morrissey CA, et al. Tissue uptake, mortality, and sublethal effects of monomethylarsonic acid (MMA(V)) in nestling zebra finches (Taeniopygia guttata). $J$ Toxicol Environ Health $A$ 2008; 71: 353-360. 2008/02/05. DOI: $10.1080 / 15287390701738566$.

8. Suzuki S, Toyoda T, Kato H, et al. Dimethylarsinic acid may promote prostate carcinogenesis in rats. $J$ Toxicol Pathol 2019; 32: 73-77. 2019/05/17. DOI: 10.1293/tox.2018-0050.

9. Weaver VM, Fadrowski JJ and Jaar BG. Global dimensions of chronic kidney disease of unknown etiology (CKDu): a modern era environmental and/ or occupational nephropathy? BMC Nephrol 2015; 16: 145. 2015/08/19. DOI: 10.1186/s12882-0150105-6.

10. Wimalawansa SJ. The role of ions, heavy metals, fluoride, and agrochemicals: critical evaluation of potential aetiological factors of chronic kidney disease of multifactorial origin (CKDmfo/CKDu) and recommendations for its eradication. Environ Geochem Health 2016; 38: 639-678. 2015/10/16. DOI: $10.1007 /$ s10653-015-9768-y.

11. Zheng L, Kuo CC, Fadrowski J, et al. Arsenic and Chronic Kidney Disease: A Systematic Review. Curr Environ Health Rep 2014; 1: 192-207. 2014/09/16. DOI: $10.1007 /$ s40572-014-0024-x.

12. Zhang Y, Young JL, Cai L, et al. Chronic exposure to arsenic and high fat diet induces sex-dependent pathogenic effects on the kidney. Chem Biol Interact 2019; 310: 108719. 2019/06/27. DOI: 10.1016/ j.cbi.2019.06.032.

13. Ishola AA, Talib NA, Muhammad N, et al. Organic Arsenical Exposure Stimulates Atherosclerosis through Oxidative Stress Increase and Adhesion Molecule Expression. Journal of Applied Pharmacentical Science 2016; 6: 040-051.

14. Andreollo NA, Santos EF, Araujo MR, et al. Rat's age versus human's age: what is the relationship? Arq Bras Cir Dig 2012; 25: 49-51. 2012/05/10. DOI: 10.1590/s0102-67202012000100011.

15. Sengupta P. The Laboratory Rat: Relating Its Age With Human's. Int J Prev Med 2013; 4: 624-630. 2013/08/10.

16. Mandal BK and Suzuki KT. Arsenic round the world: a review. Talanta 2002; 58: 201-235. 2008/10/31.
17. Edition F. Guidelines for drinking-water quality. WHO chronicle 2011; 38: 104-108.

18. Peters BA, Hall MN, Liu X, et al. Creatinine, arsenic metabolism, and renal function in an arsenic-exposed population in Bangladesh. PLoS One 2014; 9: e113760. 2014/12/02. DOI: 10.1371/ journal.pone.0113760.

19. Cui X and Okayasu R. Arsenic accumulation, elimination, and interaction with copper, zinc and manganese in liver and kidney of rats. Food Chem Toxicol 2008; 46: 3646-3650. 2008/10/14. DOI: 10.1016/j.fct.2008.09.040.

20. Orr SE and Bridges CC. Chronic Kidney Disease and Exposure to Nephrotoxic Metals. Int J Mol Sci 2017; 18 2017/05/13. DOI: 10.3390/ ijms18051039.

21. Kamal A. Estimation of blood urea (BUN) and serum creatinine level in patients of renal disorder. Indian J Fundam Appl Life Sci 2014; 4: 199-202.

22. Mohssen M. Biochemical and histopathological changes in serum creatinine and kidney induced by inhalation of Thimet (Phorate) in male Swiss albino mouse, Mus musculus. Environ Res 2001; 87: 31-36.

23. Gounden V and Jialal I. Renal Function Tests. StatPearls. Treasure Island (FL), 2020.

24. Moledina DG, Hall IE, Thiessen-Philbrook H, et al. Performance of Serum Creatinine and Kidney Injury Biomarkers for Diagnosing Histologic Acute Tubular Injury. Am J Kidney Dis 2017; 70: 807-816. 2017/08/29. DOI: 10.1053/ j.ajkd.2017.06.031.

25. De Silva PM, Mohammed Abdul KS, Eakanayake EM, et al. Urinary Biomarkers KIM-1 and NGAL for Detection of Chronic Kidney Disease of Uncertain Etiology (CKDu) among Agricultural Communities in Sri Lanka. PLoS Negl Trop Dis 2016; 10: e0004979. 2016/09/20. DOI: 10.1371/ journal.pntd.0004979.

26. Rysz J, Gluba-Brzozka A, Franczyk B, et al. Novel Biomarkers in the Diagnosis of Chronic Kidney Disease and the Prediction of Its Outcome. Int J Mol Sci 2017; 18 2017/08/05. DOI: 10.3390/ ijms18081702.

27. Delanaye P, Rozet E, Krzesinski JM and Cavalier E. Urinary NGAL measurement: biological variation and ratio to creatinine. Clin Chim Acta 2011; 412: 390. 
28. Bataille A, Tiepolo A, Robert T, et al. Reference change values of plasma and urine NGAL in cardiac surgery with cardiopulmonary bypass. Clin Biochem 2017; 50: 1098-1103.

29. Ning M, Mao X, Niu Y, Tang B and Shen H. Usefulness and limitations of neutrophil gelatinaseassociated lipocalin in the assessment of kidney diseases. Journal of Laboratory and Precision Medicine 2018; 3.

30. D'Agati VD, Fogo AB, Bruijn JA and Jennette JC. Pathologic classification of focal segmental glomerulosclerosis: a working proposal. Am J Kidney Dis 2004; 43: 368-382.

31. Lentini P, Zanoli L, Granata A, et al. Kidney and heavy metals - The role of environmental exposure (Review). Mol Med Rep 2017; 15: 3413-3419.

32. Li Z, Piao F, Liu S, Wang Y and Qu S. Subchronic exposure to arsenic trioxide-induced oxidative DNA damage in kidney tissue of mice. Exp Toxicol Pathol 2010; 62: 543-547.

33. Shafique S, Naseem N, Javaid QU and Nagi AH. Histopathological Changes in Arsenic Kushta Induced Nephrotoxicity in Wistar Rats. J Coll Physicians Surg Pak 2017; 27: 92-96. 